\title{
Search for the advancement of the International Journal of Clinical Oncology (IJCO)
}

\author{
Kazue Ozawa
}

Published online: 4 December 2014

(C) Japan Society of Clinical Oncology 2014

Two decades ago the first International Journal of Clinical Oncology (IJCO) was published. Thanks to our members' efforts, the journal has since gone from strength to strength, with papers now being submitted from outside Japan. I am delighted to see such positive progress. We were diffident at first as to how to proceed. From among the many recommendations for publishers we had received, I had to deliberate carefully as the chairman of the editorial committee. I met the manager for discussions and decided to choose Springer.

Our priority was to assert the uniqueness of the Japan Society of Clinical Oncology (JSCO), clearly differentiating our society from Japan Cancer Society. We needed to emphasize the journal's specialization in clinical practice. Each field of research has its own attraction. To my mind, basic research and clinical research are fundamentally different. Basic research is motivated by the investigation of the phenomena of life sciences, and is thus closer to the laws of nature. Clinical research is motivated by the desire to improve therapeutic outcomes by applying the knowledge that the basic scientists have discovered. This motivation should determine the choice for the subject of research.

The major task for IJCO now is to raise its quality even higher so that our presence becomes fully established in the world. Authors of papers obviously want their research published in a journal with a bigger impact factor. Therefore, we must make our journal more attractive. I would like to outline below my ideas on how to achieve this.

Evaluating papers is an exceedingly difficult task. The editors have to excel in knowledge and experience. However regrettable it is, we do find instances of discovery

\footnotetext{
K. Ozawa $(\square)$

Japan Society of Clinical Oncology, Kyoto, Japan

e-mail: office@jsco.or.jp
}

after publication that there were evident errors and inappropriate judgment. Cases that are not within the scope of scientific investigation or papers that are lacking in objective reasoning may not have been detected through further checks or peer reviews. Such papers must have been the products of distortion or fabrication. Given this context, for IJCO to be a better journal, we need to encourage original research that is reproducible. Even if a research paper has an impact, we must not shower excessive praise on non-continuous research such as degree theses. We should not be influenced by current trends but uphold continuity and have a clear sense of direction. We must continue publishing papers that are firmly grounded in lasting research principles. My greatest desire is to see the research that is "only one" yet long-lasting. Renowned international journals carry papers on innovative research conducted by numerous groups. IJCO's mission is to focus on treatments of cancer including chemotherapy et al. The research involves many subjects, necessitating accurate statistical analysis. This means that in world-class journals, the analyses of the effects of medicines are now requiring randomized prospective study rather than retrospective study. IJCO must follow suit.

Another point I wish to make is that the senior author who is the key figure in writing the paper must constantly endeavor hard, invest trust in group members and give timely and appropriate guidance. The direction of the research project must be clearly defined. Members of the group must respect the originality of other members. Support from the first class leading researchers with respect to the subject must be obtained. As I grow older, I realize the importance of delegating to others the mundane affairs of life, if you want to stay at the cutting edge of research. Meanwhile, your must never forgo the love of your own lifework, and you must continue to have the reverberation 
about the research. Something that you like doing will never leave your mind, even when you are asleep. Such constant mental delving would lead to unexpected discovery. If one research topic leads to a solution, the important thing is to turn that into the basis for the next research topic. In the process of such ongoing development, serendipity can often strike and your project may come to completion.

My personal experience is this. After finishing my first degree, I specialized in brain surgery. I started researching brain mitochondria (Mt), focusing on the fact that when the brain is starved of oxygen, the decreased level of consciousness results in a serious complication associated with multiple organ failure in the patient. However, it is not ethically permissible to separate out Mt from a human brain and manipulate it. After having devoted 10 years or so on brain surgery, I switched to liver surgery from my strong desire to apply Mt research findings into clinical practice. After this change of course, I ascertained the fact that liver Mt functions have a strong regulatory role on all functions of other organs and I proposed the Redox theory. I then developed a kit that can accurately identify liver Mt functions. This kit enabled surgeons to perform extended liver resection with greater safety on hepatocellular carcinoma with liver cirrhosis. Thereafter, we progressed to an international collaborative research based on the Redox theory. Led by three leading universities of the world (University of Hannover, University of Pittsburgh, UCLA), more than 600 cases of cadaveric liver transplantation were analyzed for effectiveness and safety. We then proceeded to living donor liver transplantation (LDLT), and until now more than 1600 cases of LDLT had been successfully performed in our hospital. From my research beginnings in Mt it took us half a century to establish a safe operative procedure of LDLT. I was fortunate to have many excellent younger doctors working with me. My heart's desire was always to conduct patient-oriented research. I managed to publish many research papers during my career. Despite my old age, I still write papers for journals, enjoying analyses of transplantation immunity based on Mt research. What I wish to stress here is that the subject of your research is not something you get given from other people. Starting as a young researcher, if you uphold your very own dream in your own clinical domain, you can discover an important finding that is most interesting and exciting. If you can tackle research from your own angle, you will not miss the opportunity serendipity offers. You will be sure to find new clues and developments.

Meanwhile, clinical research must begin with humanity, caring for your patients. In other words, the fundamental and important things are "tireless devotion to patients who are suffering from illness" and "warmth of mind as a human being." I wish to say to all readers that research can only begin if these foundations have been properly laid.

Finally looking back on my experience of the running of our society, we have to admit that academic contributions had suffered sometimes from rivalry among different disciplines and management on mostly mundane matters, at board and council levels. Looking to the future, I hope that the younger generation will have their input, breaking down barriers between domains. It is essential that translational research is conducted, linking up basic and clinical research in clinical oncology. New knowledge should always be made available to clinical practice. I would like to see a strong drive for reform so that IJCO can fulfil its mission and advance to greater success.

Kazue Ozawa

Editor-in-Chief Emeritus

International Journal of Clinical Oncology 